\title{
DEMOCRATIZAÇÃO DO ENSINO SUPERIOR: NO CONTEXTO DA EDUCAÇÃO BRASILEIRA
}

\author{
DEMOCRATIZACIÓN DE LA EDUCAÇÓN SUPERIOR: EN EL CONTEXTO DE \\ LA EDUCACIÓN BRASILEÑA
}

\section{DEMOCRATIZATION OF HIGHER EDUCATION: IN THE CONTEXT OF BRAZILIAN EDUCATION}

\author{
Rosa Maria Segalla SILVA ${ }^{1}$ \\ Nicéa Quintino AMAURO ${ }^{2}$ \\ Paulo Vitor Teodoro de SOUZA ${ }^{3}$ \\ Guimes RODRIGUES FILHO ${ }^{4}$
}

RESUMO: O presente artigo objetiva em apresentar os resultados de uma pesquisa teórica que busca investigar a (des)articulação entre a educação básica e o ensino superior, no contexto do sistema educacional brasileiro. Para tanto, é discutido neste artigo, três importantes temas que apresentam pontos fundamentais da pesquisa: o histórico das avaliações para o ingresso em Instituições de Ensino Superior (IES); o processo formativo de democratização do ensino; e, a articulação entre a educação básica e superior. Iniciamos a discussão com o vestibular no Brasil, a partir de 1911, ano em que os exames de admissão aos cursos superiores foram normatizados, e consolidamos a discussão, ao final do trabalho, com o Exame Nacional do Ensino Médio (Enem). Inferimos que a articulação entre a educação básica e o ensino superior, em muitos casos, não acontece de forma satisfatória, principalmente devido ao ensino conteudista, pragmático, memorístico e mecânico, característicos do atual sistema educacional brasileiro, especialmente nas séries finais da educação básica.

PALAVRAS-CHAVE: Processo seletivo. Democratização do ensino. Ensino superior.

RESUMEN: En este artículo se presentan los resultados de una investigación teórica que estudia la desarticulación entre la educación secundaria y la formación post-secundaria en el sistema educativo brasileño. El estúdio es discutido através de tres importantes temas que presentan puntos fundamentales en la investigación: panorama histórico de los mecanismos de selección utilizados para el ingreso a instituciones formativas post-secundarias o de nível terciario; el proceso de democratización de la enseñanza; y, la articulación entre la educación secundaria y la terciaria. Iniciamos la discución con el examen de ingreso a las universidades

${ }^{1}$ Mestra pelo Programa de Pós-Graduação em Química (PPQ) da Universidade Federal de Uberlândia (UFU). Email: rosasegala@yahoo.com.br

${ }^{2}$ Doutora em Ciências pela Universidade de São Paulo (USP). Professora no Instituto de Química da Universidade Federal de Uberlândia (UFU). Credenciada no Programa de Pós-Graduação em Ensino de Ciências e Matemática (PPGECM) da UFU. Email: niceaufu@gmail.com

${ }^{3}$ Mestre em Ensino de Ciências pela Universidade Federal de Uberlândia (UFU). Doutorando no Programa de Pós-Graduação em Educação em Ciências (PPGEduC) da Universidade de Brasília (UnB). Professor no Instituto Federal de Educação, Ciência e Tecnologia Goiano (IF Goiano) - Campus Catalão. Email: paulovitorteodoro@yahoo.com.br

${ }^{4}$ Doutor em Química pela Universidade Federal de São Carlos (UFSCar). Professor Titular no Instituto de Química da Universidade Federal de Uberlândia (UFU). Credenciado no Programa de Pós-Graduação em Química (PPQ) da UFU. Email: guimes@ufu.br 
Brasileñas a partir de 1911, año en que los exámenes de admisión a las instituciones superiores fueron normatizados, y consolidamos la discución, al final del trabajo, con el Exame Nacional do Ensino Médio (Enem). Inferimos que la articulación entre la educación secundaria y la terciaria, en muchos casos, no ocurre de forma satisfactoria, devido principalmente al método pasivo, pragmático, memorístico y mecânico del actual sistema educativo brasileño, especialmente en los últimos años de la educación secundaria.

PALAVRAS CLAVE: Proceso de selección universitária. Democratización de la educación. Educación superior.

ABSTRACT: This article objective in presenting the results of a theoretical research that investigates the selection processes of access to higher education. Therefore, it is discussed in this article, three important themes of fundamental points of our research: the history of reviews for entry into higher education institutions (HEI); the formation process of democratization of education; and the link between basic and higher education. We started the discussion with college entrance in Brazil, from 1911, the year in which the entrance examinations to higher education courses were standardized and consolidated the discussion at the end of work, with the National Secondary Education Examination (Enem). We infer that the link between basic education and higher education, in many cases, does not happen satisfactorily, mainly due to the teaching being pragmatic, mechanical, greatly based on the contents and memorization, characteristic of the current Brazilian educational system, especially in series end of basic education.

KEYWORDS: Selection process. Democratization of teaching. Higher education.

\section{Introdução}

O entendimento dos processos avaliativos da educação brasileira se relaciona com múltiplos fatores imbricados na organização e desenvolvimento educacional. Nesse sentido Cortella (1987) argumenta que os níveis educacionais fazem parte de um sistema e, portanto, os processos seletivos tais como o vestibular e o Exame Nacional do Ensino Médio (Enem), demandam estratégias e metodologias de ensino para o conjunto global da educação brasileira. Todavia persiste a falta de articulação entre as Instituições de Ensino Superior (IES) e a educação básica.

Atualmente, no Brasil, tem-se uma política de democratização para o acesso ao ensino superior. Nesse contexto, Manzini (2008) argumenta que o "acesso" deve ser compreendido como o "ingresso" à universidade, atrelado a "permanência" do estudante na instituição. Por sua vez, Coelho (1987) pondera que as discussões sobre os processos seletivos de acesso aos cursos superiores não podem se limitar a questões essencialmente técnicas, mas deve abordar também seus aspectos sociopolíticos. 
Diante disso, o presente trabalho apresenta resultados de uma pesquisa que busca analisar como e se acontece a articulação entre a educação básica e o ensino superior, no contexto do sistema educacional brasileiro. Considerando os breves aspectos apontados, desvelaremos, neste artigo, três importantes temas que fundamentam a pesquisa: (1) o histórico das avaliações para o ingresso nas IES; (2) o processo formativo de democratização do ensino; e, finalmente, (3) a (des)articulação entre a educação básica e superior.

\section{Breve histórico sobre os processos de ingresso na educação superior}

Em 1911, o exame de admissão ao ensino superior foi normatizado com a promulgação dos decretos 8.661 e 8.662, ambos de 5 de abril daquele ano, que aprovavam, respectivamente, os regulamentos das faculdades de Medicina e de Direito. De acordo com esses decretos, os candidatos deveriam apresentar, no ato da matrícula, os seguintes documentos: certidão de idade, provando ter, no mínimo, 16 anos; atestado de idoneidade moral; certificado de aprovação no exame de admissão; e, recibo da taxa de matrícula.

Concomitantemente, o exame de admissão era regulamentado pelo decreto $\mathrm{n}^{\circ}{ }^{\mathrm{o}}$ 8.659/11, de 5 de abril de 1911, que aprovava a Lei Orgânica do Ensino Superior e do Fundamental na República, que em seu artigo 65, traz o seguinte enunciado:

Para a concessão da matrícula, o candidato passará por um exame que habilite a um juízo de conjunto sobre o seu desenvolvimento intelectual e capacidade para empreender eficazmente o estudo das matérias que constituem o ensino da faculdade. (Grifo nosso).

A partir do acima exposto, arguimos que o exame de admissão para o ingresso no ensino superior caracterizava-se por uma ausência de caráter seletivo. Por sua vez, a preocupação na elaboração desses exames era o de aferir, de forma global, o desenvolvimento intelectual do candidato e a de avaliar sua capacidade para dar continuidade aos estudos em nível superior, sem estabelecer vínculo a carreiras ou cursos específicos (RIBEIRO NETO, 1987). Nesse contexto, o objetivo do exame era o de habilitar o candidato a frequentar os cursos superiores.

Nesse cenário, os exames eram compostos por duas avaliações, como descreve o primeiro parágrafo do decreto n. ${ }^{\circ} 8.661 / 15$ : “O exame de admissão a que se refere este 
artigo constará de prova escrita em vernáculo, que revele a cultura mental que se quer verificar e de uma prova oral sobre línguas e ciências".

Faz-se oportuno destacar que o baixo caráter seletivo do exame, assim como os pressupostos adotados como referência na elaboração desse deve-se ao reduzido contingente que se candidatava as vagas, sendo esses oriundos da pequena parcela da sociedade que compunha a elite brasileira.

Segundo Falcon (1987), em 1915, o Decreto n. ${ }^{\circ} 11.530$ de 18 de março reorganizou o ensino secundário (atual ensino médio) e o ensino superior em todo o país, mas manteve as características dos exames de admissão. Nesse mesmo ano, segundo Gauche (2011), a palavra vestibular foi utilizada pela primeira vez. Contudo, no período republicano, principalmente a partir da década de 1920,

\begin{abstract}
Alterações mais ou menos profundas na sociedade brasileira tiveram repercussões no sentido de passagem de um modelo predominante rural e agrário para um modelo urbano-industrial. Este processo crescente de urbanização e industrialização vai aos poucos modificar as condições de oferta e demanda de escolarização para as classes médias emergentes, num primeiro momento, e, em seguida, para as classes trabalhadoras. (FRANCO, 1987, p. 11).
\end{abstract}

No período Vargas (1930 a 1945), o fim da República Velha assinalou um momento de mudanças significativas, propiciadas pelo movimento de renovação e expansão educacional. Com o Estado Novo, mesmo com uma maior organização do sistema educacional, não houve mudanças significativas no que se refere ao acesso ao ensino superior. Visto que, o quadro elitizante do modelo educacional concernente ao ensino superior ainda predominava. Falcon (1987) afirma que,

\footnotetext{
Embora "Vargas não tivesse ideias claras sobre a educação", o clima de euforia que se instalou com a Revolução deveria atingir também o setor educacional que se deu em 1931, com a criação do Ministério da Educação e Saúde, que teve em Francisco Campos seu Primeiro Ministro com o lema: "Sanear e educar o Brasil". Na mesma época, criou-se o Conselho Nacional de Educação, que teve um papel fundamental na organização das Universidades brasileiras. (p.205).
}

As transições no modelo de sociedade descrita anteriormente justificam o crescimento considerável da relação candidato/vaga nos processos seletivos desde a década de 1950, período conhecido como o do "desenvolvimentismo" de Kubitschek (1950/1960), e principalmente na década de 1960. Nessa década, segundo Castaldo 
(2009), a crescente demanda por vagas era desproporcional à expansão do sistema universitário. Nesse cenário, a aprovação dos candidatos nos exames não era garantia de vaga, surgindo, a partir de então, a figura do "excedente".

A unificação do processo seletivo/vestibular, determinada pelo artigo 21 da Lei orgânica n. ${ }^{\text {o. }}$ 5.540/68, constituiu-se uma resposta do estado para esse problema. Em consonância ao raciocínio anterior, Ribeiro Neto (1987) defende que o aumento do número de candidatos e a insuficiência do número de vagas transformou o vestibular num "instrumento para descartar, e não selecionar candidatos" (p.19). Conforme Falcon (1987), com a promulgação da referida lei, eliminava-se definitivamente a figura do "excedente", pois, a partir de então, o vestibular não seria mais classificatório, e sim eliminatório.

Com relação às questões dos exames naquela época, o autor supracitado afirma que houve uma elevação do seu grau de dificuldade, tornando-as inconciliáveis com o que de fato era lecionado no então segundo grau (atual ensino médio, no Brasil). Tais questões das provas dos exames caracterizavam-se por serem altamente seletivas em detrimento a seu caráter avaliador. Diante desse quadro, acentuou-se ainda mais o distanciamento entre a IES e a escola de educação básica.

De acordo com Amauro (2010), em 1925, com a reforma Rocha Vaz, os exames para o ingresso no ensino superior deixaram de ser habilitatórios e passaram a ter caráter classificatório, ou seja, a garantia de vaga estava condicionada não apenas à aprovação do candidato, mas a sua classificação entre o número de vagas disponibilizado. Desse modo, como afirma a mesma autora, "[...] moldou-se o vestibular como conhecemos, acentuando o caráter seletivo/discriminatório do exame" (p. 16).

Em 1964 foi instituída a Fundação Carlos Chagas, por um grupo de professores impulsionados pela busca por racionalização e aperfeiçoamento do vestibular no âmbito das escolas médicas. A partir daí, os processos seletivos experimentaram mudanças substanciais.

Ribeiro Neto (1987) pontua algumas dessas mudanças: incluir, além das matérias tradicionais na área de Biologia, as de Matemática e Inglês; substituição do caráter habilitador pelo classificatório, como descrito anteriormente; introdução da prova de nível intelectual para a medida, principalmente, da capacidade de raciocínio verbal e numérico dos candidatos; adoção de testes objetivos de múltipla escolha como um instrumento capaz de fornecer objetividade de julgamento, além de possibilitar a correção em computador; a unificação do processo seletivo e a instituição de um 
sistema de opções prévias, sucessivas, indicadas pelos candidatos no ato da inscrição, retratando a ordem de suas preferências. De acordo com Castaldo (2009), em 1971, com o Decreto $n^{\circ} \cdot 6.908 / 71$, iniciava-se a centralização do processo de seleção no país:

O processo de unificação do vestibular culminou com o surgimento oficial da Fundação Universitária para o Vestibular, FUVEST, em 20 de Abril de 1976. O primeiro vestibular organizou-se em duas etapas: a primeira, com questões de múltipla escolha, e a segunda, com provas analítico-expositivas ou discursivas e redação [...]. (Ribeiro Neto, 1987, p 70).

O modelo outrora implementado pela Fundação Universitária para o Vestibular (Fuvest) influencia até hoje o os processos seletivos em todo o país (CASTALDO, 2009). Nas décadas de 1980 e 1990, segundo Carvalho (2012), a prova passou a avaliar todo o conhecimento adquirido na educação básica em questões de múltipla escolha. À medida que aumentava a concorrência pelas vagas no ensino superior público, fazia-se necessária a existência de questões difíceis, detalhistas, que valorizavam a memória em detrimento de outras habilidades, como a criatividade, a interpretação e a proposição.

Nesse contexto, a dificuldade das questões é associada ao detalhe, associada à memória. As demais habilidades e competências tornam-se menos importantes, para Carvalho (2012), as questões "não estimulavam a compreensão mais verticalizada dos conteúdos, a transdisciplinaridade dos saberes, sua relação dos conhecimentos com a vida prática, nem o desenvolvimento de um raciocínio crítico" (p.13). As discussões em torno do processo de ingresso em cursos superiores tomaram novos rumos a partir do ano 1987. Franco (1987) traduziu bem o novo foco dado ao tema:
A questão do acesso à universidade torna-se, na maior parte das vezes, ou uma discussão técnica onde predominam as considerações sobre os mecanismos do processo seletivo, as provas e testes, ou constitui-se de estudos sobre a influência da origem socioeconômica dos candidatos nos níveis de desempenho no vestibular. A ampliação da discussão se faz, em geral, em torno das repercussões do concurso do vestibular no $2^{\circ}$ grau [...].
Uma minoria dos estudos específicos sobre a questão do acesso a universidade, natureza e função do vestibular esboça a preocupação com os aspectos culturais e políticos. (FRANCO, 1987, p. 9).

Vinculada a essa concepção, Cortella (1987) afirma que "Discutir vestibular só faz sentido (enquanto atividade social) quando se tem uma visão mais clara do papel da Universidade frente à realidade brasileira atual; do contrário, é delinquência acadêmica" (p. 161). Voltando a temática para o cenário da avaliação, entendeu-se não ser possível 
pensar o vestibular sem pensá-lo como parte de um sistema educacional e, como tal, no seu papel social dentro de um determinado grupo.

Por ser esse o enfoque maior que pretendemos dar em nossos estudos concernentes ao processo de ingresso no ensino superior e suas implicações sobre a educação básica, trazemos também o argumento de Franco (1987) sobre a sua complexidade: “[...] o concurso vestibular não é uma questão simples. Sua complexidade advém, primeiro, do fato de ser um instrumento privilegiado de ação política do Estado" (p. 9).

Essas novas percepções nas discussões sobre o vestibular norteariam a elaboração das novas políticas públicas, que trariam embutidas os novos ideais sociais, entre eles o da democratização da educação superior, elucidando, dessa forma, o importante papel social das IES.

Diante deste quadro, desde 1996 o vestibular deixou de ser a única forma de ingresso no ensino superior. De acordo com a Lei de Diretrizes e Bases da Educação Nacional (LDBEN), em seu artigo 51, as IES credenciadas deliberarão sobre os critérios e normas de seleção e admissão de estudantes. Tal diretriz foi normatizada pelo parecer de n. ${ }^{\circ}$ CP 98/99, aprovado no dia 7 de julho de 1999, pelo Conselho Nacional de Educação - Conselho Pleno, que regulamenta o processo seletivo de acesso a cursos de graduação em Instituições de Ensino Superior. Segundo o parecer, o relator descreve:

\footnotetext{
Vale ressaltar desde logo que os concursos vestibulares continuam a ser processo válido para ingresso no ensino superior; a inovação é que deixaram de ser o único e exclusivo mecanismo de acesso, podendo as instituições desenvolver e aperfeiçoar novos métodos de seleção e admissão alternativos que, a seu juízo, melhor atendam aos interesses e às suas especificidades. (BRASIL, 1999, p.2).
}

Nesse contexto, surgiram os novos formatos de processos seletivos de ingresso ao ensino superior, denominados processos alternativos. A LDBEN afirma também, em seu artigo 51, que fica a cargo das IES estabelecer os critérios e normas de seleção para a admissão de estudantes em seu processo seletivo. Para tanto, é preciso levar em consideração as consequências de tais processos sobre a educação básica. Uma grande mudança que o Brasil experimentou nesses últimos anos, em termos de processo seletivo, foi a criação do Enem, em 1998.

Carvalho (2012) discute que, após 1998, com a criação do Enem, as mudanças nos processos de reformulação do ensino médio acentuaram-se. Para o autor, a LDBEN 
abriu caminho para uma nova organização curricular pautada pela contextualização dos saberes e por sua integração e articulação, ou seja, pela interdisciplinaridade.

A institucionalização do Enem mudaria as matrizes norteadoras na elaboração de questões que comporiam as provas do exame. Num primeiro momento, o exame tinha como único objetivo a avaliação do ensino médio, mas, a partir de 2007, o exame pôde ser usado para substituir, em parte ou na sua totalidade, as provas do processo seletivo nas Universidades cadastradas no Sistema de Seleção Unificada (Sisu) do Ministério da Educação (MEC).

As mudanças nos processos seletivos de ingresso aos cursos superiores, nas últimas décadas, foram substanciais, especialmente no concernente ao processo de democratização da IES e ao combate à discriminação racial no nosso país. Prova disso foi a promulgação da lei de n. ${ }^{\circ} 12.711$, de 29 de agosto de 2012, a conhecida Lei das Cotas Étnico-Raciais e Sociais. Segundo o Laboratório de Políticas Públicas da Universidade Estadual do Rio de Janeiro (2013), em Jornal Informativo Conexões Impressas, pesquisas realizadas pela Associação Nacional dos Dirigentes das Instituições Federais de Ensino Superior (Andifes) demonstram que houve um progressivo e contundente reconhecimento da importância das cotas no país, sendo mais da metade dos reitores e das reitoras das Universidades e Institutos Federais já favoráveis às cotas.

A Lei das Cotas Étnico-Raciais e Sociais dispõe sobre o ingresso nas Universidades Federais e Institutos Federais. De acordo com o primeiro artigo da referida lei:

As instituições federais de educação superior vinculadas ao Ministério da Educação reservarão, em cada concurso seletivo para ingresso nos cursos de graduação, por curso e turno, no mínimo 50\% (cinquenta por cento) de suas vagas para estudantes que tenham cursado integralmente o ensino médio em escolas públicas. (BRASIL, 2012).

De acordo com Dias Sobrinho (2010), a Lei das Cotas constitui uma das principais iniciativas das ações afirmativas que o MEC vem impulsionando, sendo uma das mais polêmicas. Segundo o mesmo autor, tais ações "[...] dão atenção especial a estudantes pobres, notadamente afrodescendentes e indígenas, jovens oriundos de escolas públicas e portadores de necessidades especiais" (p. 1.234).

Entendemos que o Enem e as leis de cunho social, especialmente a Lei das Cotas, constituem instrumentos do MEC que visam à garantia de igualdade de 
condições para o acesso ao ensino superior. Atualmente, o processo seletivo para o ingresso no ensino superior é muito mais do que um exame que classifica os melhores candidatos; ele também precisa garantir que cidadãos, especialmente oriundos das classes menos privilegiadas da sociedade, tenham igualdade de condições para competirem por vagas para continuarem os estudos. Essas mudanças poderão promover um novo contexto sociopolítico dos processos seletivos, contribuindo com o processo de democratização do ensino superior.

\section{Democratização do ensino superior}

Ao refletirmos sobre as políticas públicas relacionadas ao processo de ingresso as IES, no primeiro momento buscamos a compreensão do termo "políticas públicas". De acordo Azevedo (1997), essas: “[...] representam a materialidade da intervenção do Estado, ou o "Estado em ação" (p. 5). Nessa direção, Azevedo (1997) sustenta que uma política pública específica para determinado grupo "[...] constitui-se a partir de uma questão que se torna socialmente problematizada. A partir de um problema que passa a ser discutido amplamente pela sociedade, exigindo atuação do Estado” (p. 61).

Assim, devido ao problema que surge em decorrência de um aumento substancial da demanda por vagas na educação superior, o estado reúne esforços na tentativa de responder à comunidade com a implementação de programas, como o Fundo de Financiamento Estudantil (Fies); o Programa Universidade para Todos (Prouni); e o Programa de Apoio a Planos de Reestruturação e Expansão das Universidades Federais (Reuni). Tais programas buscam atender os objetivos do Plano

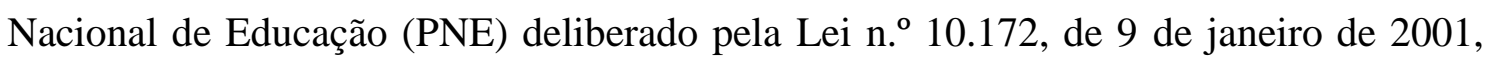
que aprova o PNE. Esse plano estabeleceu, entre outras metas, a de ofertar a Educação Superior para, pelo menos, 30\% da população na faixa etária de 18 a 24 anos até 2012.

Segundo dados do Instituto Nacional de Estudos e Pesquisas Educacionais “Anísio Teixeira” (Inep), o número de matrículas no Ensino Superior aumenta a cada ano: de 107.509 em 1962, passou para 1.438 .992 em 1983. No início do século XXI, em 2003, o número de matrículas nas IES quase duplicou em relação à década anterior: 3.887.002; e, em 2012, esse número foi para 7.037.688 de matrículas (BRASIL/MEC/INEP, 2012), caracterizando um aumento substancial da oferta de vagas na Educação Superior. 
Nesse novo cenário, é preciso verificar dois aspectos importantes relacionados à questão da democratização do Ensino Superior. O primeiro remete-nos ao seguinte questionamento: os ingressantes no Ensino Superior que preencheram as novas vagas disponibilizadas pelo sistema educacional pertencem a qual fração da população brasileira? Para Dias Sobrinho (2010), "É ainda muito pequena a parcela da massa dos pobres brasileiros que conseguem fazer um longo e bom percurso escolar" (p. 129). Cumpre evidenciar que, segundo o resultado da Pesquisa Nacional por Amostragem de Domicílios (Pnad), de 2007, realizada pelo Instituto Brasileiro de Geografia e Estatística (IBGE), menos de 3\% dos estudantes da Educação Superior pertencem ao quinto mais pobre da população nacional, ao qual pertencem 30,2 \% das famílias brasileiras. A partir da análise dos dados apresentados na Tabela 1, podemos comparar os índices apontados anteriormente com os dados atuais.

Tabela 1 - Estudantes da rede pública e da rede particular, nos ensinos Fundamental, Médio e Superior, total e respectiva distribuição percentual, segundo os quintos de rendimento mensal familiar per capita - Brasil - 2011.

\begin{tabular}{|c|c|c|c|c|c|c|}
\hline \multirow{3}{*}{$\begin{array}{l}\text { Quintos de rendimento mensal } \\
\text { familiar per capita }\end{array}$} & \multicolumn{6}{|c|}{ Estudantes } \\
\hline & \multicolumn{2}{|c|}{ Ensino fundamental } & \multicolumn{2}{|c|}{ Ensino médio } & \multicolumn{2}{|c|}{ Ensino superior } \\
\hline & Rede pública & Rede particular & Rede pública & Rede particular & Rede pública & Rede particular \\
\hline \multicolumn{7}{|c|}{ Números absolutos (1 000 pessoas) (1) } \\
\hline \multirow[t]{2}{*}{ Total } & 26169 & 3731 & 7196 & 1017 & 1469 & 4304 \\
\hline & \multicolumn{3}{|c|}{ Distribuição percentual (\%) } & & & \\
\hline $1^{2}$ quinto & 38,0 & 6,4 & 22,4 & 3,8 & 7,1 & 3,5 \\
\hline $2^{2}$ quinto & 28,3 & 13,3 & 26,7 & 7,5 & 10,2 & 6,6 \\
\hline $3^{2}$ quinto & 18,2 & 16,0 & 23,1 & 13,4 & 16,4 & 13,5 \\
\hline $4^{2}$ quinto & 11,0 & 21,7 & 19,2 & 22,0 & 25,3 & 28,1 \\
\hline $5^{2}$ quinto & 4,5 & 42,6 & 8,6 & 53,2 & 41,0 & 48,3 \\
\hline
\end{tabular}

Fonte: IBGE, Pesquisa Nacional por Amostra de domicílios 2001/2011.

Os dados refletem uma nova realidade, apontando um avanço significativo em relação ao cenário descrito anteriormente, com um aumento de sete pontos percentuais em quatro anos. Atinge, portanto, em 2011, um percentual de 10,6\%, correspondente à soma dos estudantes de IES da rede pública e instituições particulares, oriundos da comunidade que representa a quinta parte mais pobre da população brasileira. Isso demonstra que as políticas públicas que visam à democratização do ensino superior já começam a mostrar algum resultado, mas não se pode desconsiderar que há muito ainda a fazer para que tais políticas se efetivem. 
Dando prosseguimento às nossas reflexões, elaboramos a Tabela 2 a partir dos dados levantados pelo Inep. Nela estão indicados o número de matrículas na educação básica, que compreende a educação infantil regular, educação fundamental regular, e o ensino médio a cada três anos a partir de 2003.

Tabela 2 - Número de matrículas por ano e modalidade de ensino na Educação Básica (2003/2012).

\begin{tabular}{cccc}
\hline Ano & $\begin{array}{c}\text { Educação } \\
\text { Infantil }\end{array}$ & $\begin{array}{c}\text { Educação } \\
\text { Fundamental }\end{array}$ & $\begin{array}{c}\text { Ensino } \\
\text { Médio }\end{array}$ \\
\hline $\mathbf{2 0 0 3}$ & 6.393 .234 & 34.438 .749 & 9.072 .942 \\
$\mathbf{2 0 0 6}$ & 7.016 .095 & 33.282 .663 & 8.906 .820 \\
$\mathbf{2 0 0 9}$ & 6.762 .631 & 31.705 .528 & $8.337 .160^{*}$ \\
$\mathbf{2 0 1 1}$ & 6.980 .052 & 30.358 .640 & $8.400 .689^{*}$ \\
$\mathbf{2 0 1 2}$ & 7.295 .512 & 29.702 .498 & $8.376 .852^{*}$ \\
\hline *Inclui matrículas no Ensino Médio integrado à Educação Profissional e no Ensino Médio normal/magistério.
\end{tabular}

Fonte: Elaboração própria, a partir de dados do BRASIL/MEC/SIMEC.

Da análise dos dados, evidenciamos que o número de matrículas na modalidade de ensino - educação infantil - é muito menor que na educação fundamental. Tal fato ocorre porque este tipo de ensino, oferecido em creches e pré-escolas para crianças com até seis anos de idade, é facultativo.

Quando comparamos os números de matrículas da Educação Fundamental com o ensino médio, temos um quadro preocupante: há uma diminuição abrupta desse número no ensino médio, chegando a ser quatro vezes menor. Essa relação mantém-se desde 2003 até 2012.

Diante dos argumentos defendidos por Dias Sobrinho (2010), corroborados pelos dados apresentados nas Tabelas 1 e 2, depreendemos que a simples expansão na oferta de vagas na educação superior não resolve o problema da democratização. Há outras questões que lhe são correlatas, como a seletividade do sistema educacional na educação básica, levando-nos a silogizar que o processo de seleção não acontece apenas no vestibular, mas durante toda a vida escolar dos estudantes.

Considerando esse contexto, Franco (1987) argumenta que "o vestibular não é a única e nem talvez a mais importante barreira de seleção [...]” (p. 11), posto que as oportunidades de acesso às IES estão cristalizadas e definidas nas condições socioeconômicas do candidato, que o referido autor acredita serem fatores determinantes no sucesso ou fracasso escolar desde a educação básica, e a garantia ou não de ingresso na educação superior. 
Nessa mesma linha de pensamento, Falcon (1987) argumenta que exame para ingresso no ensino superior, especialmente o vestibular na década de 1970, explicitava "[...] algo que existia independentemente de sua forma, isto é, o fato de que os mais bem classificados são aqueles que tiveram condições socioeconômicas para cursar os melhores colégios e fazer os cursinhos" (p. 208), se referindo aos cursos preparatórios nas instituições particulares de ensino. E que, portanto, como salienta Jardim (1987): “O vestibular real desnuda a intenção aparentemente democratizante do vestibular legal, elegendo para a graduação não os mais capazes, mas os oriundos das classes socioeconômicas mais favorecidas" (p. 214). Esse argumento desvela a realidade do processo de democratização do ensino superior no Brasil, especialmente no preenchimento das vagas de cursos mais concorridos, como Medicina, Direito e Engenharias.

Nesse cenário, entendemos que a lei das Cotas propicia uma ruptura de paradigma, na medida em que possibilita uma maior representatividade de alunos pertencentes a classes sociais desfavorecidas da sociedade nos cursos de maior concorrência supracitados.

Bem sabemos que os programas citados anteriormente representam soluções paulatinas, sendo necessário combater os problemas de uma educação superior elitizada, como consequência da falta de qualidade no ensino na educação básica, especialmente nas instituições públicas de ensino. Um dos problemas relacionados à má formação dos discentes na educação básica pode estar relacionado ao baixo capital cultural desses estudantes. As diferenças nas condições de aprendizagem entre aprendizes das classes mais pobres que frequentam as escolas públicas e os educandos das classes mais abastadas que frequentam as escolas particulares são gigantescas. Tais situações comprometem a sua formação básica, podendo inviabilizar o prosseguimento de seus estudos.

A segunda questão intimamente ligada à democratização da Educação Superior que analisaremos é: os estudantes que ingressam no ensino superior permanecem até a conclusão de seus estudos? Buscando a resposta para essa pergunta, construímos a Tabela 3, a partir de dados fornecidos pelo Inep. 
Tabela 3 - Número de matrículas e de alunos concluintes no Ensino Superior Brasil -1963/2010.

\begin{tabular}{ccc}
\hline Ano & $\begin{array}{c}\text { Número de matrículas } \\
\text { no Ensino Superior }\end{array}$ & $\begin{array}{l}\text { Número de alunos } \\
\text { concluintes } \\
\text { do Ensino Superior }\end{array}$ \\
\hline $\mathbf{1 9 6 3}$ & 124.214 & 19.049 \\
$\mathbf{1 9 7 3}$ & 772.800 & 135.339 \\
$\mathbf{1 9 8 3}$ & 1.438 .992 & 238.339 \\
$\mathbf{1 9 9 3}$ & 1.594 .668 & 240.269 \\
$\mathbf{2 0 0 3}$ & 3.887 .022 & 528.223 \\
$\mathbf{2 0 1 0}$ & 6.407 .733 & 980.662 \\
\hline
\end{tabular}

Fonte: Elaboração própria, a partir de dados do BRASIL/MEC/SIMEC.

Mediante análise dos dados da tabela acima, percebemos que de uma década para a outra o número de matrículas na educação superior aumentou expressivamente, fato que denota grandes avanços na aplicação das políticas de ampliação da oferta de vagas em IES. Outro aspecto de grande relevância é a diferença evidente entre o número de matrículas nos cursos superiores e o número de estudantes que concluem seus estudos, o que nos permite inferir, a partir da pergunta anterior, que a permanência de boa parte dos discentes no ensino superior não está sendo assegurada. A partir do exposto, sumarizamos que o processo de democratização da educação superior está em desenvolvimento, mas existem ainda grandes desafios a serem superados para a sua consolidação.

Nesse contexto, o Estado vem investigando essas questões ligadas à democratização do ensino superior e tem se empenhado na busca por soluções que deverão atenuar tais discrepâncias. Segundo Amauro (2010), além da demanda quantitativa, a procura pelo acesso ao ensino superior é também exercida pelos contingentes de alunos de escola pública, como também grupos étnico-raciais, que requerem inclusão. A última mobilização do MEC com o objetivo de minimizar estas diferenças sociais que perduram por séculos foi a elaboração da Lei n. ${ }^{\circ} 12.711$, de 29 de agosto de 2012, conhecida como "Lei de Cotas". De acordo com tal norma, as IES públicas devem reservar cinquenta por cento do número de vagas oferecidas, por curso e por turno, para alunos egressos da educação básica oriundos de escola pública, até 2016. As vagas reservadas às cotas levarão em conta o percentual mínimo correspondente ao da soma de pretos, pardos e indígenas no Estado, de acordo com o último censo demográfico do IBGE.

Concomitantemente, notamos que as ações do Estado na busca pela democratização do ensino superior são plausíveis. Arruda (2011) compartilha desse 
ponto de vista ao afirmar que "[...] há um empenho do governo federal em instituir políticas de expansão mais abrangentes, porém, o cunho de justiça social dos programas ainda é campo de embates [...]" (p. 508).

É preciso fazer da própria IES um ambiente profícuo de discussões que visam ao enfrentamento desses desafios e, consequentemente, sua superação, para a tão esperada democratização do ensino superior. Essas discussões devem priorizar os aspectos sociais e políticos intrínsecos ao sistema de educação brasileiro, a fim de que, a partir de uma melhor compreensão deles, vislumbremos caminhos que apontem modificações não apenas nos processos seletivos, que implicariam mudanças meramente técnicas, como modificações no formato dos exames, forma de aplicação e modelos de questões para a sua constituição.

É necessário pensar os processos seletivos de ingresso nas IES como parte de um sistema, o qual deve ser estudado no contexto sociopolítico do país. Para Brandão (1987), isso acontecerá quando as IES

\begin{abstract}
Abrir as suas portas, para que nela ingresse a sociedade real que somos. Sociedade esta que deverá tornar-se o objeto primeiro de estudo dos que aí chegaram, dentro de uma ótica de profunda consonância com as aspirações mais legítimas da maioria da população brasileira, impedida de usufruir dos frutos de seu próprio trabalho no processo de desenvolvimento deste país. (p. 172).
\end{abstract}

O que significará, sobretudo, a garantia de acesso ao ensino superior não apenas para uma pequena fração da população brasileira, mas para a maioria dos brasileiros, especialmente aqueles oriundos das classes menos privilegiadas da comunidade, atendendo, assim, as suas aspirações genuínas e promovendo o desenvolvimento de uma sociedade que buscar ser mais igualitária.

\title{
Os processos seletivos e a (des)articulação entre a IES e a educação básica
}

Os processos seletivos de acesso ao Ensino Superior, pensados como parte do sistema educacional, são alvo de muitos debates. Os exames vêm ao longo do tempo sofrendo alterações importantes, como afirma Franco (1987):

Com a emergência de novas classes e grupos sociais, com a perda ou conquista de poder político e econômico ao longo do processo 
histórico, alteram-se as condições de existência da população, assim como as inter-relações entre a sociedade e a educação. (p. 11).

Como o autor descreve, tais modificações são perceptíveis principalmente nas duas últimas décadas. Especialmente após a promulgação da LDBEN, que trata, em seu artigo 51, da tentativa de articulação entre a IES e a Educação Básica:

As instituições de educação superior credenciadas como universidades, ao deliberar sobre critérios e normas de seleção e admissão de estudantes, levarão em conta os efeitos desses critérios sobre a orientação do ensino médio, articulando-se com os órgãos normativos dos sistemas de ensino. (BRASIL, 1996, grifo nosso).

Articulação que, muitas vezes, não acontece de forma satisfatória, principalmente devido ao ensino conteudista, característica marcante do sistema educacional brasileiro na atualidade, especialmente nas séries finais da educação básica, que prima pela preparação do aluno para ingresso ao nível de ensino subsequente.

Cumpre evidenciar também, ainda sobre o artigo supracitado, o efeito dos critérios (utilizados pelas IES para a seleção de candidatos) sobre a orientação no ensino médio, devendo ser considerados pelas IES na elaboração de seus processos seletivos, o que poderá propiciar uma maior articulação entre a educação superior e básica, especialmente no ensino médio.

Nesse cenário, é de grande relevância compreender a transição de um modelo tradicional de processo seletivo para um novo modelo que se caracteriza, principalmente, pela autonomia dada às IES para a criação de formas alternativas de ingresso a seus cursos. Daremos ênfase às reflexões e ponderações que primam pela questão da articulação, ou talvez, desarticulação, entre o ensino médio e o ensino superior, sendo, portanto, dentre outras, uma das aspirações que nos levaram ao campo de pesquisa.

É importante ainda destacar que a tentativa de articulação entre esses níveis de ensino é uma preocupação antiga. À guisa de exemplo, o decreto 8.569, de 1911, em seu artigo 69, retrata que a educação básica não deve estar atrelada aos caprichos da educação superior, posto que essa articulação muitas vezes acontece pelo seu lado negativo, que enfatiza um sistema de ensino propedêutico.

A imposição de uma política de desenvolvimento econômico, nas décadas de 1960 e 1970, que primava pelos investimentos em educação, aliada à divulgação massiva do discurso subjacente de que o caminho para a ascensão social estava na 
obtenção de níveis cada vez mais altos de escolaridade, podem ser as causas que levaram à cristalização do ensino nas escolas brasileiras, acentuando ainda mais o caráter enciclopédico do processo de ensino-aprendizagem (FRANCO, 1987).

Tendo em vista a preocupação das IES em relação às implicações de seus processos seletivos sobre a educação básica, entendemos que os discursos de tais instituições, muitas vezes, remetem ao seu comprometimento com o desenvolvimento da qualidade da educação básica. Mas, como sabemos, muitas vezes pode haver entre o discurso e a prática uma grande lacuna. Manzano (2011) compartilha desse ponto de vista ao afirmar que: "Apesar deste discurso socialmente responsável de comprometimento com a melhoria da qualidade do ensino médio [...]", continua o autor, ao se referir aos processos seletivos seriados de ingresso as IES, aqueles que acontecem ao final de cada série e ao longo do ensino médio, "[...] a adoção do conteúdo programático das avaliações seriadas caracteriza de uma forma mais perversa o caráter propedêutico do ensino médio" (p. 52).

\section{Considerações Finais}

Consideramos, neste artigo, discussões e reflexões que acreditamos ser importantes para o sistema educacional, especialmente na transição da educação básica para o ensino superior. Para tanto, as discussões sobre o histórico das avaliações para o ingresso nas IES, como o vestibular e o Enem, o processo formativo de democratização do ensino, bem como a articulação entre a educação básica e superior, favoreceu as nossas considerações, especialmente de que existe uma desarticulação entre o ensino básico e superior, mas que o Brasil pode avançar no caminho para a melhoria da educação, embora ainda temos que prosseguir nas discussões sobre a qualidade e público-alvo e sobre os exames de seleção.

A escola brasileira tem como princípio da educação básica, em especial o ensino médio, a preparação dos seus alunos para o enfrentamento de processos seletivos, principalmente, para a educação superior. Essa concepção de escola pode deixar a prática docente engessada a exercícios complexos, memorísticos e mecânicos, nos quais pouco colabora para a aprendizagem e desenvolvimento cognitivo dos estudantes.

No entanto, sabemos que essa é uma preocupação do professor, a qual está atrelada ao processo de legitimação da escola como um espaço responsável por 
promover o desenvolvimento do educando, possibilitando o ingresso no ensino superior. A existência do discurso subjacente de que para o cidadão conseguir melhores condições de vida precisa fazer um curso superior implica o seguinte raciocínio: quanto maior o número de alunos que a escola promove, melhor é a qualidade do seu ensino. No entanto, segundo Castro (2012), os processos seletivos para o ensino superior podem enfraquecer as forças para a diversificação da educação básica, principalmente o ensino médio.

Desta forma, a partir de toda a discussão feita, apreendemos que as influências dos processos seletivos de ingresso às IES são nitidamente reconhecidas, até mesmo em níveis que antecedem o ensino médio na educação básica.

Esperamos que este trabalho contribua com outras pesquisas que enveredam a discutir sobre este tema. Sabemos a necessidade do tema em questão ainda perpassar por diversos embates e discussões, seja sobre os vestibulares ou o exame unificado de prova, atualmente representado pelo Enem. Para isso, acreditamos que mudanças no sistema educacional brasileiro venham a acontecer verticalmente, ocasionando uma ruptura do engessamento ao qual está submetida a escola básica, para que, desta forma, sejam implementados ambientes que possam, de fato, corroborar no ensino de qualidade.

\section{Referências}

AMAURO, N. Q. Os concursos vestibulares das universidades estaduais paulista e o ensino de Química no nível médio. 2010. 156 f. Tese (Doutorado em Ciências) Universidade de São Paulo, São Paulo, 2010.

ARRUDA, A. L. B. Políticas da educação superior no Brasil: expansão e democratização: um debate contemporâneo. Espaço do Currículo, João Pessoa, v. 3, n. 2, p. 501-510, 2011.

AZEVEDO, J. M. L. A educação como política pública. Campinas, SP: Autores Associados, 1997.

BRANDÃO, Z. O processo de seletividade social e o vestibular. In: BRASIL. Ministério da Educação. Seminários vestibular hoje. Brasília, DF, 1987. p. 165-175.

BRASIL. Ministério da Educação. Conselho Nacional de Educação. Parecer 98/99. Lex: Regulamentação de Processo Seletivo para acesso a cursos de graduação de Universidades, Centros Universitários e Instituições de Isoladas de Ensino Superior. Brasília, DF, 1999. 
Brasil. Lei n. ${ }^{0}$ 9.394, de 20 de dezembro de 1996 - Lei de Diretrizes e Bases da Educação Nacional.

BRASIL. Lei n. ${ }^{\circ}$ 12.711, de 29 de agosto de 2012. Dispõe sobre o ingresso nas universidades federais e nas instituições de ensino técnico de nível médio e dá outras providências. Brasília, 2012.

BRASIL. Ministério da Educação. Instituto Nacional de Estudos e Pesquisas Educacionais Anísio Teixeira. Disponível em: < http://portal.inep.gov.br/web/censo-daeducacao-superior/evolucao-1980-a-2012>. Acesso em 14 de set. 2015.

BRASIL. Ministério da Educação. SIMEC. Painel de controle do Mec. Disponível em: $<$ http://painel.mec.gov.br/painel.php?modulo=principal/detalhamentoIndicador\&acao= A\&detalhes=pais\&indid=442>. Acesso em 23 de mar. 2015.

CASTALDO, M. M. Redação no vestibular: a língua cindida. 2009. 277 f. Tese (Doutorado) - Universidade de São Paulo, São Paulo, 2009.

CASTRO, C. M. Reitores mandam no ensino médio. O Educacionista. 2012. Disponível em: <http://www.educacionista.org.br/jornal/index.php?option=com_content\&task=view\&i $\mathrm{d}=14821 \&$ Itemid=43> . Acesso em 22 fev. 2015.

CARVALHO, E. Os poderes do Vestibular: da construção da hegemonia a ao prenúncio da queda. In: HISTÓRIA EDUCAÇÃO E SOCIEDADE: demandas e tendências, 2., 2012, Goiânia. Anais... Goiânia [S. 1], 2012. Disponível em: $<$ http://www.academia.edu/5074039/OS_PODERES_DO_VESTIBULAR_da_construc ao_da_hegemonia_ao_prenuncio_da_queda>. Acesso em: 22 fev. 2015.

COELHO, I. M. Aspectos políticos do vestibular. In: BRASIL. Ministério da Educação. Seminários vestibular hoje. Brasília, DF, 1987. p. 189-196.

CORTELLA, M. S. Relação entre o vestibular e o sistema educacional. In: BRASIL. Ministério da Educação. Seminários vestibular hoje. Brasília, DF, 1987. p. 161-163.

DIAS SOBRINHO, J. Dilemas da educação superior no mundo globalizado: sociedade do conhecimento ou economia do conhecimento? São Paulo: Casa do Psicólogo, 2010.

FALCON, M. C. A. S. O vestibular: uma questão política. In: BRASIL. Ministério da Educação. Seminários vestibular hoje. Brasília, DF, 1987. p. 203-212.

FRANCO, M. A. C. Acesso à universidade: uma questão política e um problema metodológico [1987].

Disponível em: <http:www.fcc.org.br/pesquisa/publicacoes/es/artigos/105.pdf>. Acesso em: 25 out. 2014.

GAUCHE, R. Interdisciplinaridade e processo seletivo para a graduação: da influência inevitável à interação desejável. In: SANTOS, C. A. dos; QUADROS, A. F. de. (Org.). Utopia em busca de possibilidade: abordagens interdisciplinares no ensino das ciências da natureza. Foz do Iguaçu: UNILA, 2011. p.147-159. 
JARDIM, G. A. F. A pseudo-democratização do concurso vestibular: alternativas de superação. In: BRASIL. Ministério da Educação. Seminários vestibular hoje. Brasília, DF, 1987. p. 213-217.

MACHADO, I. F. Conflitos em avaliação de aprendizagem. 1996. 193f. Dissertação. (Mestrado em Educação) - Faculdade de Educação da Universidade Estadual de Campinas - Campinas, São Paulo, 1996.

MANZANO, E. M. Vestibular seriado: estado da arte e a percepção docente sobre o tema. 75 f. Dissertação (Mestrado) - Universidade de São Paulo, São Paulo, 2011.

MANZINI, E. J. Acessibilidade: um aporte na legislação para o aprofundamento do tema na área de educação. In: BAPTISTA, C. R.; CAIADO, K. R. M.; JESUS, D. M.(Org.). Educação Especial: Diálogo e Pluralidade. Porto Alegre: Ed. Mediação, 2008. p. 281-289.

RIBEIRO NETO, A. O vestibular ao longo do tempo: Implicações e implicâncias. In: BRASIL. Ministério da Educação. Seminários vestibular hoje. Brasília, DF, 1987. p. 17-27.

\section{Como referenciar este artigo}

SILVA, Rosa Maria Segalla et al. Democratização do ensino superior: no contexto da educação brasileira. Revista Ibero-Americana de Estudos em Educação, Araraquara/SP, v.12, n.1, p. 294-312 2017. Disponível em: <http://dx.doi.org/10.21723/riaee.v12.n1.8256>. E-ISSN: 1982-5587.

Data de submissão: dez/2015

Aprovação final: dez/2016 